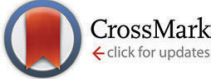

Cite this: Chem. Commun., 2017 53,1374

Received 17th December 2016, Accepted 6th January 2017

DOI: $10.1039 / c 6 c c 10040 f$

www.rsc.org/chemcomm

\section{Symmetry breaking above room temperature in an Fe(II) spin crossover complex with an $\mathrm{N}_{4} \mathrm{O}_{2}$ donor set $\dagger$}

\author{
Wasinee Phonsri, ${ }^{a}$ Casey G. Davies, ${ }^{b}$ Guy N. L. Jameson, ${ }^{b}$ Boujemaa Moubaraki, ${ }^{a}$ \\ Jas S. Ward, ${ }^{c}$ Paul E. Kruger, ${ }^{c}$ Guillaume Chastanet $^{d}$ and Keith S. Murray*a
}

\begin{abstract}
[Fe(qsal- $\mathrm{Cl})_{2}$ ] is one of the few known Fe(II) spin crossover compounds with an $\mathrm{N}_{4} \mathrm{O}_{2}$ donor atom environment. It shows an abrupt two-step spin transition at 308 and $316 \mathrm{~K}$ and importantly, symmetry breaking at the highest temperature reported, to date, in spin crossover compounds.
\end{abstract}

The study of spin crossover (SCO) materials continues to generate a great deal of interest from both fundamental and applied perspectives. ${ }^{1-6} \mathrm{Fe}(\mathrm{II}) \mathrm{d}^{6}$ and $\mathrm{Fe}(\mathrm{III}) \mathrm{d}^{5}$ compounds remain the metal systems of choice in these studies. Within these systems, mixed N/O-ligand donor sets are well known for Fe(III) but rare for $\mathrm{Fe}(\mathrm{II})$ SCO complexes. ${ }^{7-16}$ Specifically, the qsal ligands are known to produce SCO with $\mathrm{Fe}(\mathrm{III}) .^{12,17-20}$ However, only one qsal derivative of $\mathrm{Fe}(\mathrm{II}),\left[\mathrm{Fe}^{\mathrm{II}}\left(\mathrm{qsal}^{-\mathrm{NO}_{2}}\right)_{2}\right]$ (qsal- $\mathrm{NO}_{2}=5$-nitro- $\mathrm{N}$-(8quinolyl)-salicylaldimine), has been reported to show SCO (incomplete) up to $400 \mathrm{~K} .{ }^{21}$ Generally, the space group symmetry of SCO compounds is unchanged following transition between different spin states. There are a limited number of compounds for which symmetry breaking takes place and accompanies complete SCO. ${ }^{22-25}$ Notably, there are only two compounds that have shown symmetry breaking in an $\left[\mathrm{Fe}^{\mathrm{II}} \mathrm{N}_{4} \mathrm{O}_{2}\right]$ system i.e. $\mathrm{Fe}(\mathrm{II})$ with a hexadentate $\mathrm{N}_{4} \mathrm{O}_{2}$ ligand, $\left[\mathrm{Fe}\left(5-\mathrm{NO}_{2} \text { - } \mathrm{Sal}-\mathrm{N}(1,4,7,10)\right)\right]^{26}$ This compound shows two-step SCO with $T_{1 / 2}$ (heating) $=136$ and $171 \mathrm{~K}$, and three different space groups at 103, 153 and $292 \mathrm{~K}$. Another example is a 1D chain of [FeL1(azpy)] where L1 is

\footnotetext{
${ }^{a}$ School of Chemistry, Monash University, Clayton, Victoria, 3800, Australia. E-mail: keith.murray@monash.edu

${ }^{b}$ Department of Chemistry \& MacDiarmid Institute for Advanced Materials and Nanotechnology, University of Otago, PO Box 56, Dunedin, 9054, New Zealand ${ }^{c}$ Department of Chemistry \& MacDiarmid Institute for Advanced Materials and Nanotechnology, University of Canterbury, Private Bag 4800, Christchurch 8041, New Zealand

${ }^{d}$ CNRS, Université de Bordeaux, ICMCB, 87 avenue du Dr A. Schweitzer, Pessac 33608, France

$\dagger$ Electronic supplementary information (ESI) available: Tables S1-S3 structural data; Table S4 review of two step symmetry breaking compounds; Tables S5 and S6 Mössbauer and DSC results; Fig. S1-S3 structures; Fig. S4-S6 photomagnetism, Mössbauer and Fig. S4 DSC results. CCDC 1495808-1495813. For ESI and crystallographic data in CIF or other electronic format see DOI: 10.1039/c6cc10040f
}

the tetradentate $\mathrm{N}_{2} \mathrm{O}_{2}$ ligand ( $\mathrm{L} 1$ = diethyl $(E, E)-2,2^{\prime}$-[1,2-phenylbis(iminomethylidyne)] bis[3-oxobutanoate]-(2-)- $\left.N, N^{\prime}, \mathrm{O}^{3}, \mathrm{O}^{3 \prime}\right) \cdot{ }^{27}$ Herein, we report the first example of symmetry breaking with re-entrant behaviour in a complex containing a tridentate $\mathrm{N}_{2} \mathrm{O}$ ligand, viz. [Fe(qsal-Cl $\left.)_{2}\right]$ 1. Interestingly, 1 shows complete, abrupt two-step SCO above room temperature, the highest temperature yet reported so far for a mononuclear SCO compound.

Complex 1 was synthesized by a multi-layering method: a dichloromethane solution of Hqsal-Cl and $\mathrm{Et}_{3} \mathrm{~N}$ formed the bottom layer; neat $\mathrm{MeOH}$ formed the middle 'buffering' layer; whilst $\mathrm{FeCl}_{2} \cdot 4 \mathrm{H}_{2} \mathrm{O}$ in $\mathrm{MeOH}$ formed the top layer. Black crystals formed in good yield within one week. Variable-temperature single crystal X-ray diffraction experiments on $\mathbf{1}$ were obtained at six temperatures, viz. 100, 298, 308, 312, 318 and $330 \mathrm{~K}$ that encompass all the different spin states observed (vide infra), Fig. $1 . \ddagger$ Intriguingly, crystals of 1 show symmetry breaking. At 100 and $298 \mathrm{~K}, 1$ exists in the monoclinic space group $P 2_{1} / n$ and a single molecule of $\mathbf{1}$ is observed in the asymmetric unit. Between 308 and $312 \mathrm{~K}$, the cell parameters $\alpha$ and $\gamma$ deviate
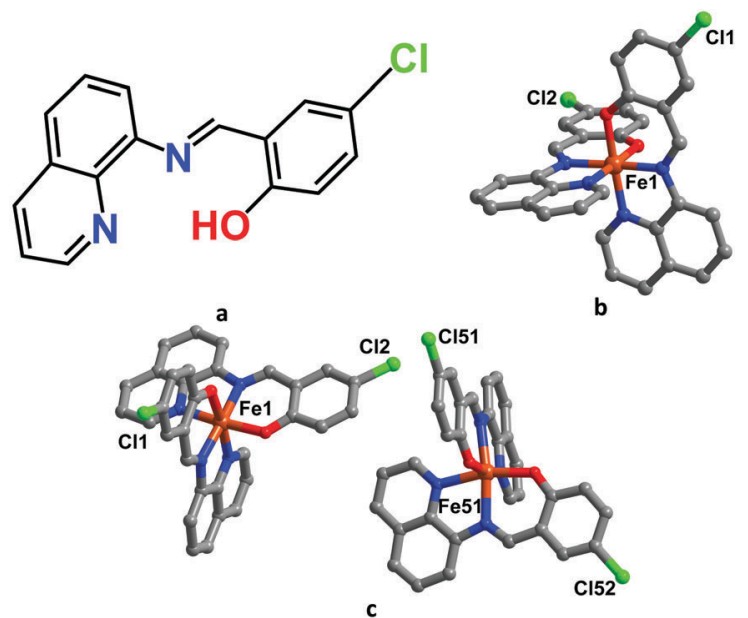

Fig. 1 Molecular structures of (a) Hqsal-Cl ligand and the asymmetric unit of 1 at (b) LS and HS state (c) intermediate states. 
significantly from $90^{\circ}$ and the symmetry changes to triclinic, $P \overline{1}$. At this intermediate stage (IP), there are two molecules of $\mathbf{1}$ in the asymmetric unit (labelled Fe1 and Fe51) with different spin states (1LS-1HS), Fig. 1c. At temperatures above $318 \mathrm{~K}$, the crystal system reverts to $P 2_{1} / n$, thus showing re-entrant behaviour.

The $\mathrm{Fe}(\mathrm{II})$ centres coordinate to $\mathrm{N}_{4} \mathrm{O}_{2}$ donors from two tridentate anionic qsal-Cl ligands chelating in meridional fashion to yield neutral 1. Fe-L bond lengths for the compound are shown in Table S2 (ESI $\dagger$ ). At 100 and $298 \mathrm{~K}, \mathrm{Fe}-\mathrm{L}$ distances $(\mathrm{Fe}-\mathrm{O} \approx 1.96$ and $\mathrm{Fe}-\mathrm{N} \approx 1.94-1.99 \AA)$ and the octahedral distortion parameters ${ }^{28,29}\left(\Sigma \approx 33^{\circ}\right.$ and $\left.\Theta=65-74^{\circ}\right)$ indicate that the $\mathrm{Fe}(\mathrm{II})$ centre is in the LS state. ${ }^{30,31}$ Upon warming the crystal of 1 to between 308 and $312 \mathrm{~K}$, there are two molecules in the asymmetric unit. The Fe-L bond lengths and octahedral distortion parameters suggest an intermediate state consisting of 1LS and 1HS Fe(II) centre in the asymmetric unit. At temperatures above $318 \mathrm{~K}$ only one molecule of $\mathbf{1}$ is again observed in the asymmetric unit, suggesting the fully HS structure exists at $330 \mathrm{~K}$ $(\mathrm{Fe}-\mathrm{O} \approx 2.01$ and $\mathrm{Fe}-\mathrm{N} \approx 2.16 \AA)$.

Although symmetry breaking is observed in $\mathbf{1}$, the packing of the Fe(II) moieties within the crystal remains unchanged, Fig. 2. The supramolecular arrangements that remain similar during the symmetry breaking have also been reported in previous systems. ${ }^{32-34}$ The deficiency of diffuse scattering and the extra Bragg reflections in the IP of compound 1 suggest that the spin transition relates to the long-range order characteristic of the IP. ${ }^{24}$

The packing in $\mathbf{1}$ is reminiscent of those seen in Fe(III)-qsal systems (albeit without the presence of an anion). ${ }^{12,35-38}$ Thus, a chain of $\mathrm{Fe}(\mathrm{II})$ moieties interact through two sets of $\pi-\pi$ interactions via sal $\cdots$ quin rings of the qsal-Cl ligands and $\mathrm{C}-\mathrm{H} \cdots \mathrm{O}$ interactions along the $b$ axis (Fig S1, ESI $\dagger$ ). Moreover, along the $a$ axis, $\mathrm{C}-\mathrm{H} \cdots \mathrm{Cl}$ interactions and two sets of parallel fourfold aryl embraces $(\mathrm{P} 4 \mathrm{AE})^{39}$ are observed to link the $\mathrm{Fe}$ moieties into higher dimension. P4AE is believed to be the reason for the observation of complete abrupt spin crossover in $\mathbf{1}^{12,40}$ (see Magnetic section). Furthermore, in the ac plane, there are two extra sets of $\pi-\pi$ interactions holding the Fe

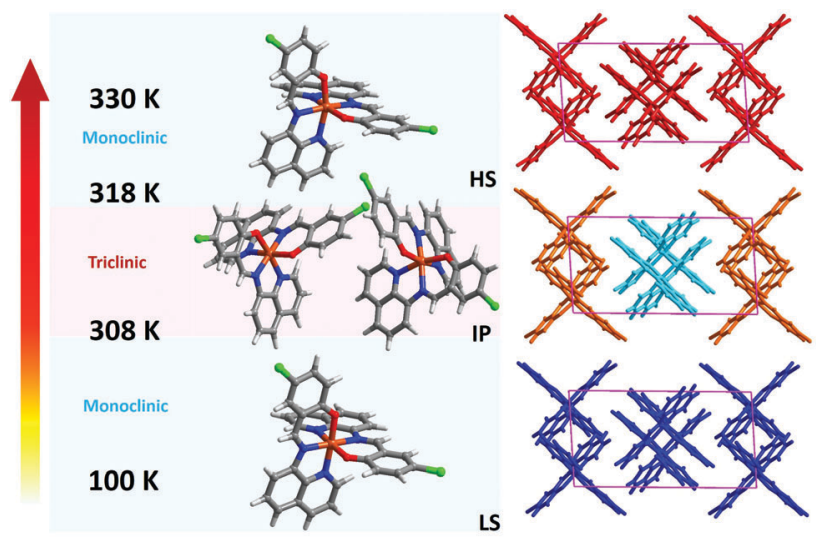

Fig. 2 Simplification of symmetry breaking showing the molecules in the asymmetric unit as well as the packing of $\mathbf{1}$, deep blue molecules in the unit cell packing represent fully LS state, orange and light blue molecules are in mostly HS and LS state, respectively and red is fully HS state of Fe(॥).

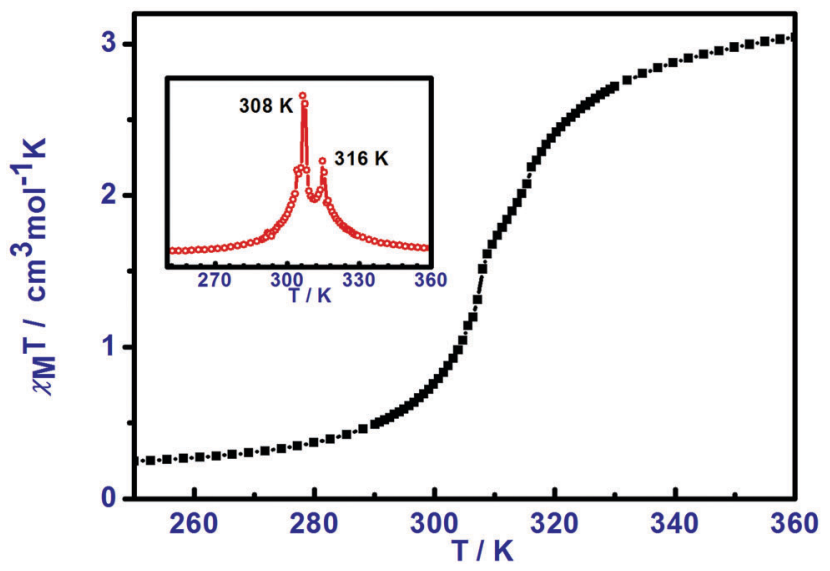

Fig. 3 Variable-temperature magnetic susceptibility $\left(\chi_{M} T\right)$ measurements for compound 1, an inset shows the first order differentiation of the magnetic plot.

molecules in the plane. It is important to note that two types of P4AE interactions and the extra two sets of $\pi-\pi$ interactions described here are not seen in Fe(III)-(qsal-X) complexes. That is because anions and/or solvents occupy spaces between the $\left[\mathrm{Fe}(\mathrm{III})(\mathrm{qsal}-\mathrm{Cl})_{2}\right]$ molecules and prevent those interactions taking place in those complexes. Such interactions are believed to be responsible for the greater cooperativity as they enhance the surface contacts between Fe(II) moieties. ${ }^{41}$ Therefore, they result in the exceptionally high spin transition temperatures observed in 1 (vide infra).

The variable-temperature magnetic susceptibility data for $\mathbf{1}$ were obtained between 100-360 K using various scan rates i.e. 2, 5 and $10 \mathrm{~K} \mathrm{~min}^{-1}$. The magnetic results for the compound are independent of the scan rate and are illustrated in Fig. 3. Upon closer inspection, together with differential scanning calorimetry results, two steps have been detected in $\mathbf{1}$ with a pseudo-plateau of width of about $8 \mathrm{~K}$. Upon heating from $100 \mathrm{up}$ to $250 \mathrm{~K}$, the $\chi_{\mathrm{M}} T$ values of 1 is invariant with temperature, with $\chi_{\mathrm{M}} T$ values of about $0.3 \mathrm{~cm}^{3} \mathrm{~K} \mathrm{~mol}^{-1}$, indicative of the LS Fe(II) forms. Upon further warming, spin crossover takes place and 1 shows a two-step transition with $T_{1 / 2}=308$ and $316 \mathrm{~K}$ for the $1 \mathrm{st}$ and 2 nd steps, respectively, before reaching the fully HS form at high temperatures. There is a small thermal hysteresis of about 1-2 $\mathrm{K}$ width present in this compound. The magnetic profiles are reproducible in subsequent cycles.

Variable temperature single crystal X-ray diffraction indicates concerted SCO and symmetry breaking in 1 via $\operatorname{LS}\left(P 2_{1} / n\right) \leftrightarrow$ $1 \mathrm{LS}-1 \mathrm{HS}(P \overline{1}) \leftrightarrow \operatorname{HS}\left(P 2_{1} / n\right)$ steps. This also agrees with the discontinuous changes of the unit cell parameters around $300 \mathrm{~K}$ (Fig S2, ESI $\dagger$ ). Thus, there is a strong correlation between SCO and structural changes in this compound.

According to the reviewed information in Table S4 (ESI $\dagger$ ), there is only a small number of examples of symmetry breaking with complete, two steps SCO that have been characterized. To the best of our knowledge, $\left[\mathrm{Fe}(\mathrm{qsal}-\mathrm{Cl})_{2}\right]$ is the first $\mathrm{Fe}$ (II) complex with a $\mathrm{N}_{2} \mathrm{O}$ ligand donor set that exhibits symmetry breaking involving a two-step SCO, above RT, the highest temperatures reported for symmetry breaking in mononuclear 
Fe-SCO compounds. The highest temperature noted previously was $\sim 250 \mathrm{~K}$.

For a deeper comparison of a related symmetry breaking Fe(III) compound, [Fe $\left.{ }^{\mathrm{III}}(\mathrm{qsal}-\mathrm{Br})_{2}\right] \mathrm{NO}_{3} \cdot 2 \mathrm{MeOH},{ }^{35} 2$ shows a twostep SCO with a large plateau of about $96 \mathrm{~K}$ while 1 has a small pseudo-plateau with width about $8 \mathrm{~K}$. Consideration of intermediate state structures shows that compound 1 and 2 both have two Fe centres, 1LS-1HS. However, these Fe centres interact in different fashion. In the case of $\mathbf{1}$, a plane of the same spin state of [Fe(II)(qsal-Cl $\left.)_{2}\right]$ is formed via two sets of $\pi-\pi$ and $\mathrm{P} 4 \mathrm{AE}$ interactions. In contrast, a chain of the same $\mathrm{Fe}(\mathrm{III})$ molecules connect, solely, through two sets of $\pi-\pi$ interactions (Fig S3, ESI $\dagger$ ). As both of the compounds show re-entrant behaviour, chains of 1LS and 1HS Fe(III) moieties in the intermediate state have to propagate through the whole compound in $2 \mathrm{D}$ and $3 \mathrm{D}$ packing to revert to $1 \mathrm{HS}$ upon heating. Whereas the 2D-plane of Fe(II) molecules in $\mathbf{1}$ is more facile to induce two unique $\mathrm{Fe}(\mathrm{II})$ sheets reaching one $\mathrm{Fe}(\mathrm{II})$ centre with fully $\mathrm{HS}$ behaviour. Such differences possibly result in a significantly narrower intermediate phase temperature gap in $\mathbf{1}$.

The effect of light irradiation on compound $\mathbf{1}$ was also studied. Irradiations at 405, 510, 650, 830 and $980 \mathrm{~nm}$ were tested with $650 \mathrm{~nm}$ irradiation inducing the most efficient photoconversion. The T(LIESST) curve was recorded. A common feature to 1 is the shape of the T(LIESST) curve. Increasing the temperature from $10 \mathrm{~K}$ in the dark, after photo-saturation was reached, induces an increase of the $\chi_{\mathrm{M}} T$ value. This usually follows from the Fe(II) zero-field splitting. ${ }^{42}$ After a maximum in the $T$ (LIESST) curve, the $\chi_{M} T$ value drops down to the base line. Regarding the photoconversion efficiency, it is $30 \%$ with $T($ LIESST $)=40 \mathrm{~K}$. An interesting point is that upon irradiation at $980 \mathrm{~nm}$, a partial depopulation of the photo-induced HS state is observed, due to the reverse-LIESST process. Compared to the relaxation in the dark measured at $10 \mathrm{~K}$ (inset in Fig. 4), the reverse LIESST is clearly operative, even if it is not complete.

The ${ }^{57} \mathrm{Fe}$ Mössbauer spectra of 1 were measured at low $(\sim 5 \mathrm{~K})$ and room temperatures to confirm the presence of LS and HS forms. The spectral parameters of the compounds are shown in Fig. 5 and Table S5 (ESI $\dagger$ ). The results are typical for $\mathrm{Fe}$ (II) complexes with quadrupole splitting, $\Delta E_{\mathrm{Q}}$, and isomer shift, $\delta$ of $c a .1$ and $0.5 \mathrm{~mm} \mathrm{~s}^{-1}$ for LS forms while they are about 2 and $1 \mathrm{~mm} \mathrm{~s}^{-1}$ for $\mathrm{HS}$ forms, respectively. ${ }^{43,44}$ For compound 1, the fully $\mathrm{Fe}$ (II) LS forms exist at low temperatures. At room temperature, some fractions of Fe(II) HS are also present. These Mössbauer data correspond well with the magnetic results confirming exceptionally high $T_{1 / 2}$ in the compounds. Unfortunately, we cannot collect the fully $\mathrm{HS} \mathrm{Fe}$ (II) spectrum as this occurs at too high a temperature for our Mössbauer facility.

Differential scanning calorimetry (DSC) data were collected on compound 1 using a $10 \mathrm{~K} \mathrm{~min}^{-1}$ scan rate. From the DSC plots in Fig. S4 (ESI $\dagger$ ), there are two peaks for endo- and exothermic measurements. All the phase transition temperatures from the DSC data are in the same range as the spin transition results from magnetic measurements. As mentioned above, the initial magnetic plot for 1 roughly suggested a one-step SCO with an abrupt spin transition. The DSC result confirms the two step SCO present in this

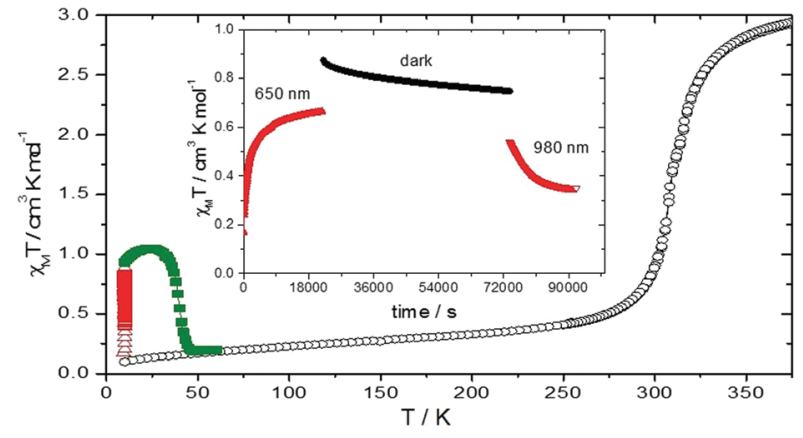

Fig. 4 Thermal behaviour of the $\chi_{M} T$ values for 1 in the dark ( $\left.O\right)$, under a $650 \mathrm{~nm}$ irradiation $(\Delta)$ and after this irradiation in the dark at $0.4 \mathrm{~K} \mathrm{~min}^{-1}$ ( $\square$ ). The inset reports the time dependence of the $\chi_{M} T$ values in 1 following irradiation at $650 \mathrm{~nm}(\Delta)$ and $980 \mathrm{~nm}(\nabla)$ compared to the relaxation in the dark at $10 \mathrm{~K}(\mathbf{\square})$

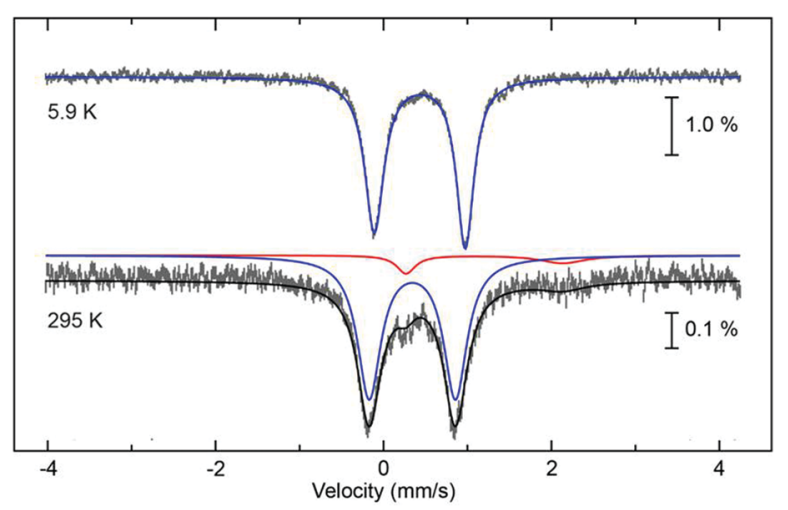

Fig. 5 Variable temperature ${ }^{57} \mathrm{Fe}$ Mössbauer spectral plots for 1 . At low temperature the sample is fully low spin (blue fit). At $295 \mathrm{~K}$ the sample is a mixture of low spin (blue) and high spin (red). Fitted parameters are given in Table S5 $($ ESI $\uparrow)$.

compound. Moreover, the small $\Delta S$ value of $19.8 \mathrm{~J} \mathrm{~mol}^{-1} \mathrm{~K}^{-1}$ in $\mathbf{1}$, agrees with data by Wang and Gao et al. who reported that symmetry breaking was also associated with a two-step SCO and led to a significant lowering in $\Delta H$ and $\Delta S$ values. ${ }^{40}$

In summary, $\left[\mathrm{Fe}(\mathrm{II})(\mathrm{qsal}-\mathrm{Cl})_{2}\right] \mathbf{1}$ has provided an unprecedented array of magnetic and spin crossover properties. It is the first $\mathrm{Fe}$ (II) compound with a $\mathrm{N}_{2} \mathrm{O}$ donor ligand to exhibit symmetry breaking accompanied by a two-step SCO above room temperature, the highest temperatures reported thus far for symmetry breaking SCO compounds (viz. $T_{1 / 2}=308$ and $316 \mathrm{~K}$ ). In general, compared to iron(III) analogues $\left[\mathrm{Fe}(\mathrm{III})(\mathrm{qsal}-\mathrm{X})_{2}\right] \mathrm{Y},{ }^{12,45}$ we propose that the abrupt SCO at such a high temperature in $\mathbf{1}$ is due to an absence of anions/solvents in the lattice that allow the Fe(II) molecules to have larger surface contact (via two extra sets of $\pi-\pi$ and P4AE interactions) than for the Fe(III) complexes which enhances the strong cooperativity. Subsequently, to design a potential spin crossover material, the fundamental requirements for an abrupt spin crossover, particularly in Fe-qsal complexes, is the combination of the symmetrical two sets of $\pi-\pi$ and P4AE interactions. To show spin transition at exceptionally high temperatures, the extra two sets of $\pi-\pi$ and P4AE interactions are further recommended. 
This work was supported by an Australian Research Council Discovery grant (to K. S. M.). P. E. K. gratefully acknowledges the Royal Society of New Zealand Marsden Fund for financial support. We thank Professor David Harding (of Walailak University, Thailand) for valuable discussions. This paper is dedicated to Professor Leone Spiccia (1957-2016), a fine person, friend and excellent scientist.

\section{Notes and references}

\$ Synthesis details and crystallographic data at variables temperatures are presented in the ESI. $\dagger$

1 R. J. Deeth, C. M. Handley and B. J. Houghton, in Spin-Crossover Materials, ed. M. A. Halcrow, John Wiley \& Sons Ltd, 2013, pp. 443-454.

2 P. N. Martinho, C. Rajnak and M. Ruben, in Spin-Crossover Materials, ed. M. A. Halcrow, John Wiley \& Sons Ltd, 2013, pp. 375-404.

3 P. Gütlich, A. Hauser and H. Spiering, Angew. Chem., Int. Ed. Engl., 1994, 33, 2024-2054.

4 A. Bousseksou, G. Molnar, L. Salmon and W. Nicolazzi, Chem. Soc. Rev., 2011, 40, 3313-3335.

5 K. S. Murray, in Spin-Crossover Materials, ed. M. A. Halcrow, John Wiley \& Sons Ltd, 2013, pp. 1-54.

6 M. A. Halcrow, Chem. Commun., 2013, 49, 10890-10892.

7 M. Nihei, T. Shiga, Y. Maeda and H. Oshio, Coord. Chem. Rev., 2007, 251, 2606.

8 P. Gütlich and H. A. Goodwin, in Spin Crossover in Transition Metal Compounds I, ed. P. Gütlich and H. A. Goodwin, Springer Berlin Heidelberg, Berlin, Heidelberg, 2004, pp. 1-47.

9 B. Weber, E. Kaps, J. Weigand, C. Carbonera, J.-F. Létard, K. Achterhold and F. G. Parak, Inorg. Chem., 2008, 47, 487-496.

10 B. Weber, W. Bauer and J. Obel, Angew. Chem., Int. Ed., 2008, 47, 10098-10101.

11 S. Dorbes, L. Valade, J. A. Real and C. Faulmann, Chem. Commun., 2005, 69-71.

12 D. J. Harding, P. Harding and W. Phonsri, Coord. Chem. Rev., 2016, 313, 38-61.

13 B. Weber, Coord. Chem. Rev., 2009, 253, 2432-2449.

14 L. Zhang, G.-C. Xu, H.-B. Xu, V. Mereacre, Z.-M. Wang, A. K. Powell and S. Gao, Dalton Trans., 2010, 39, 4856-4868.

15 L. Zhang, G.-C. Xu, Z.-M. Wang and S. Gao, Eur. J. Inorg. Chem., 2013, 1043-1048.

16 T. Romero-Morcillo, M. Seredyuk, M. C. Muñoz and J. A. Real, Angew. Chem., Int. Ed., 2015, 54, 14777-14781.

17 S. Hayami, Z.-z. Gu, H. Yoshiki, A. Fujishima and O. Sato, J. Am. Chem. Soc., 2001, 123, 11644-11650.

18 K. Takahashi, H. Mori, H. Kobayashi and O. Sato, Polyhedron, 2009, 28, 1776-1781.

19 D. J. Harding, D. Sertphon, P. Harding, K. S. Murray, B. Moubaraki, J. D. Cashion and H. Adams, Chem. - Eur. J., 2013, 19, 1082-1090.
20 K. Fukuroi, K. Takahashi, T. Mochida, T. Sakurai, H. Ohta, T. Yamamoto, Y. Einaga and H. Mori, Angew. Chem., Int. Ed., 2014, 53, 1983-1986.

21 O. Iasco, E. Rivière, R. Guillot, M. Buron-Le Cointe, J.-F. Meunier, A. Bousseksou and M.-L. Boillot, Inorg. Chem., 2015, 54, 1791-1799.

22 K. Nakano, S. Kawata, K. Yoneda, A. Fuyuhiro, T. Yagi, S. Nasu, S. Morimoto and S. Kaizaki, Chem. Commun., 2004, 2892-2893.

23 N. Bréfuel, H. Watanabe, L. Toupet, J. Come, N. Matsumoto, E. Collet, K. Tanaka and J.-P. Tuchagues, Angew. Chem., Int. Ed., 2009, 48, 9304-9307.

24 D. Chernyshov, M. Hostettler, K. W. Törnroos and H.-B. Bürgi, Angew. Chem., Int. Ed., 2003, 42, 3825-3830.

25 N. Ortega-Villar, M. Muñoz and J. Real, Magnetochemistry, 2016, 2, 16.

26 D. Boinnard, A. Bousseksou, A. Dworkin, J. M. Savariault, F. Varret and J. P. Tuchagues, Inorg. Chem., 1994, 33, 271-281.

27 W. Bauer, T. Pfaffeneder, K. Achterhold and B. Weber, Eur. J. Inorg. Chem., 2011, 3183-3192.

28 J. K. McCusker, A. L. Rheingold and D. N. Hendrickson, Inorg. Chem., 1996, 35, 2100-2112.

29 M. Marchivie, P. Guionneau, J.-F. Letard and D. Chasseau, Acta Crystallogr., Sect. B: Struct. Sci., 2005, 61, 25-28.

30 L. Zhang, G.-C. Xu, H.-B. Xu, T. Zhang, Z.-M. Wang, M. Yuan and S. Gao, Chem. Commun., 2010, 46, 2554-2556.

31 T. Kuroda-Sowa, Z. Yu, Y. Senzaki, K. Sugimoto, M. Maekawa, M. Munakata, S. Hayami and Y. Maeda, Chem. Lett., 2008, 37, 1216-1217.

32 T. M. Ross, B. Moubaraki, K. S. Wallwork, S. R. Batten and K. S. Murray, Dalton Trans., 2011, 40, 10147-10155.

33 H. Watanabe, N. Bréfuel, E. Collet, L. Toupet, K. Tanaka and J.-P. Tuchagues, Eur. J. Inorg. Chem., 2013, 710-715.

34 S. Bonnet, M. A. Siegler, J. S. Costa, G. Molnar, A. Bousseksou, A. L. Spek, P. Gamez and J. Reedijk, Chem. Commun., 2008, 5619-5621.

35 D. J. Harding, W. Phonsri, P. Harding, K. S. Murray, B. Moubaraki and G. N. L. Jameson, Dalton Trans., 2015, 44, 15079-15082.

36 D. J. Harding, W. Phonsri, P. Harding, I. A. Gass, K. S. Murray, B. Moubaraki, J. D. Cashion, L. Liu and S. G. Telfer, Chem. Commun., 2013, 49, 6340-6342.

37 K. Takahashi, T. Sato, H. Mori, H. Tajima and O. Sato, Phys. B, 2010, 405, S65-S68.

38 D. Sertphon, D. J. Harding, P. Harding, K. S. Murray, B. Moubaraki, J. D. Cashion and H. Adams, Eur. J. Inorg. Chem., 2013, 788-795.

39 V. Russell, M. Scudder and I. Dance, J. Chem. Soc., Dalton Trans., 2001, 789-799.

40 W. Zhang, F. Zhao, T. Liu, M. Yuan, Z.-M. Wang and S. Gao, Inorg. Chem., 2007, 46, 2541-2555.

41 M. A. Halcrow, in Spin-Crossover Materials, ed. M. A. Halcrow, John Wiley \& Sons Ltd, 2013, pp. 147-169.

42 J.-F. Letard, J. Mater. Chem., 2006, 16, 2550-2559.

43 P. Gütlich, Y. Garcia and H. A. Goodwin, Chem. Soc. Rev., 2000, 29, 419-427.

44 O. Hietsoi, P. W. Dunk, H. D. Stout, A. Arroyave, K. Kovnir, R. E. Irons, N. Kassenova, R. Erkasov, C. Achim and M. Shatruk, Inorg. Chem., 2014, 53, 13070-13077.

45 W. Phonsri, PhD thesis, Walailak University, Thailand, 2014. 